RAE-IC, Revista de la Asociación Española de Investigación de la Comunicación

vol. 8, núm. 15 (2021), 469-495

ISSN 2341-2690

Recibido el 23 de julio de 2020

DOI: https://doi.org/10.24137/raeic.8.15.21

Aceptado el 15 de diciembre de 2020

\title{
Desmatamento e crise ambiental. Uma análise do enquadramento das políticas públicas na mídia digital
}

Deforestation and environmental crisis. An analysis of the framework of public policies in digital media

de Campos, Mariane Motta

Universidade Paulista (UNIP)

marianemottadecampos@hotmail.com

Fernandes, Carla Montuori

Universidade Paulista (UNIP)

carla_montuori@ig.com.br

Ribeiro Cardoso, Viviane Amélia

Universidade Federal de Juiz de Fora (UFJF)

vivianecardoso@gmail.com

Forma de citar este artículo:

De Campos, M. M. Fernandes, C. M y Ribeiro Cardoso, V. A. (2021). Desmatamento e crise ambiental. Uma análise do enquadramento das políticas públicas na mídia digital. RAE-IC, Revista de la Asociación Española de Investigación de la Comunicación, 8(15), 469-495. https://doi.org/10.24137/raeic.8.15.21 


\section{Resumen:}

O jornalismo ocupa um papel de destaque nas sociedades democráticas ao contribuir no processo de propagação e ampliação do debate junto à opinião pública sobre temas que são considerados cruciais para a humanidade. A presente pesquisa traz um estudo do enquadramento noticioso dado pelos sites O Antagonista e The Intercept Brasil, acerca das políticas públicas ligadas ao meio ambiente, tendo como recorte as reportagens que trataram das queimadas na floresta Amazônica durante o mês de agosto de 2019. A pesquisa responde como os respectivos jornais on-line enquadraram o debate sobre o desmatamento da Amazônia em um contexto de crise ambiental.O estudo tem como hipótese que os jornais on-line buscaram um enquadramento polarizado sobre o tema, mas se distanciaram da discussão sobre as políticas públicas que estão vinculadas a proteção ambiental e seus entraves. Como metodologia recorreu-se a análise de enquadramento noticioso, partindo da noção que os conteúdos da mídia abrigam uma estrutura interna que possui uma ideia central organizadora conceituada por pacotes interpretativos.

Palabras clave: crise ambiental, floresta amazónica, enquadramento, jornalismo, meio ambiente

\section{Abstract:}

Journalism plays a prominent role in democratic societies by contributing to the process of spreading and expanding the debate with public opinion on topics that are considered crucial for humanity. The present research brings a study of the news framework given by the websites $\mathrm{O}$ Antagonista and The Intercept Brasil, about public policies related to the environment, with the clipping of the articles that dealt with the burning in the Amazon forest during the month of August 2019. The research answers how the respective online newspapers framed the debate on deforestation in the Amazon in a context of environmental crisis. The study hypothesizes that online newspapers sought a polarized framework on the topic, but distanced themselves from the discussion about 
policies that are linked to environmental protection and its barriers. As a methodology, the analysis of news framing was used, starting from the notion that the media content houses an internal structure that has a central organizing idea conceptualized by interpretive packages.

Keywords: environmental crisis, Amazon rainforest, framework, journalism, environment

\section{INTRODUÇÃO}

O presente artigo tem como objetivo analisar a problemática do meio ambiente, a partir da abordagem conferida pelo jornalismo on-line, com o intuito de identificar como foi enquadrado a questão das políticas públicas voltadas para a questão ambiental, durante o mês de agosto de 2019, quando se registrou o aumento das incidências de queimadas na floresta Amazônica.

Barros (2016, p. 198) argumenta que a mídia exerce, principalmente no Brasil, um forte papel no letramento cultural e informacional, já que "grande parte do conhecimento e da experiência vividos pelas audiências acerca de assuntos de relevância social, política, econômica e cultural passa, necessariamente, pelo enquadramento das mídias, que se tornaram fonte primordial de informação". Nesse sentido, compreender o impacto da mídia na vida dos cidadãos, no âmbito das políticas públicas, torna-se fundamental.

Na esfera governamental, Penteado e Fortunato (2015) atentam que as políticas públicas são mecanismos de ação do Estado sobre a sociedade, que por meio da administração pública e de seus agentes, atuam sobre determinadas questões com o objetivo de promover o desenvolvimento social. Diante do atual cenário de reorganização do papel do Estado e suas distintas formas de intervenção social, o debate acerca das políticas públicas tem dominado grande parte das agendas midiáticas, e tem alcançado maior visibilidade durante o governo do Presidente Jair Bolsonaro (PSL). Para retomar tal narrativa se faz necessário elencar o processo histórico pelo qual o pleito eleitoral de 2018 foi conduzido. 
As eleições de 2018 para Presidente da República estiveram inseridas em um contexto de desgaste da imagem de partidos tradicionais e lideranças políticas, ruptura de alianças, mudanças na legislação eleitoral e pelo crescente uso estratégico da internet nas campanhas. A ruptura de alianças partidárias no âmbito nacional, como a aliança de anos entre PT e (P)MDB, elevou o número de concorrentes da disputa. Ao todo, 13 candidatos disputaram o cargo para Presidente da República. São eles: Jair Bolsonaro, Fernando Haddad (PT), Ciro Gomes (PDT), Geraldo Alckmin (PSDB), João Amoêdo (NOVO), Cabo Daciolo (PATRI), Henrique Meirelles (MDB), Marina Silva (REDE), Álvaro Dias (PODEMOS), Guilherme Boulos (PSOL), Vera Lúcia (PSTU), José Maria Eymael (DC) e João Goulart Filho (PPL). No primeiro turno, Bolsonaro recebeu 49.277.010 votos (46\%), já Haddad 31.342.051 votos (29,28\%). Já no segundo turno, Bolsonaro com $55,13 \%$ dos votos $(57.797 .847)$ venceu Haddad (44,87\% - 47.040.906). No primeiro turno a eleição ocorreu 7 de outubro de 2018, já no segundo turno, 28 de outubro.

Durante o período de campanha eleitoral, Bolsonaro já se mostrava contrário às entidades ambientais e mais favorável ao agronegócio, sendo que no início do primeiro mandato uma crise começou a se instaurar com a demissão de Ricardo Galvão do comando do Instituto Nacional de Pesquisas Espaciais (INPE), após o órgão divulgar o aumento do número de desmatamento da Amazônia. Outras medidas também devem ser consideradas, como a nomeação de Ricardo Salles para a pasta, criticado por não ter ligação histórica com o ambientalismo e por ser acusado de ter fraudado mapas do Plano de Manejo da Área de Proteção Ambiental Várzea do Rio Tietê, quando era secretário do Meio Ambiente no governo de São Paulo ${ }^{1}$. Além disso, em janeiro de 2019, o Ministério do Meio Ambiente suspendeu convênios e parcerias com Organizações e Entidades não governamentais ligadas à área ambiental, causando ainda mais indisposição com a classe.

Com menos de um ano de governo, o Presidente Bolsonaro enfrentou múltiplas crises, entre as quais a ocorrência de muitos focos de incêndio na Amazônia, chamando a

1Justiça de SP condena futuro ministro do Meio Ambiente por improbidade administrativa. Disponível em: https://g1.globo.com/sp/sao-paulo/noticia/2018/12/19/justica-de-sp-condena-futuro-ministro-do-meio-ambiente-porimprobidade-administrativa.ghtml Acesso em: 20 de set. de 2019. 
atenção de Organizações Não Governamentais (ONGs) e de países europeus preocupados com a questão ambiental. Diante da alta repercussão midiática do evento, divulgado em grande medida pela imprensa nacional e internacional, o governo passou a sofrer ataques e pressão de países como França, Alemanha e Noruega, de entidades ambientais e até mesmo de representantes do agronegócio que temiam pela queda da exportação devido à situação.

Dessa forma, compreender como a mídia enquadrou esse momento de crise e qual a visibilidade conferida às políticas públicas ambientais torna-se importante tendo em vista o papel de centralidade da mídia para a formação da opinião pública. As teorias contemporâneas do jornalismo trabalham a perspectiva de que as notícias são um processo de construção social complexo que envolve múltiplos fatores, como a linha editorial, os critérios de noticiabilidade, a dependência das fontes, os recursos disponíveis e as rotinas de produção.

Destaca-se a teoria do enquadramento (Goffman, 1986) que trabalha com a ideia de que os jornais, ao selecionarem determinados fatos, enfatizam alguns aspectos a partir de mapas culturais, excluindo outros elementos. Dessa forma é importante compreender qual foi a narrativa sobre as políticas públicas ambientais, conferido pela mídia digital, que via de regra possui maior autonomia que a imprensa tradicional, sobretudo porque são menos suscetíveis as pressões do campo político e econômico. A produção jornalística acaba por sofrer influência de fatores externos às redações, em especial de instituições que por vezes são anunciantes e ao mesmo tempo estão envolvidas com a poluição ambiental. Tal fator pode inibir a produção de notícias sobre o tema.

Dessa maneira, será utilizada a metodologia o Enquadramento (Gamson e Modigliani, 1993; Maia e Vimieiro, 2011), a fim de analisar os enunciados veiculados pelos sites de notícias $O$ Antagonista e The Intercept Brasil, em que se trate da crise ambiental gerada com o aumento das queimadas na região da Amazônia. A escolha pelos objetos de estudo se justifica diante da importância das mídias digitais na sociedade 
contemporânea, de tal maneira que ela não pode mais ser considerada como algo separado das instituições culturais e sociais ${ }^{20}$.

A ascensão e a consolidação da web 2.0 , nomeada de segunda geração de serviços e utilizações da internet vai potencializar as formas de publicação, compartilhamento e organização das informações, ampliando os espaços para a interação entre os participantes do processo. Seu desenvolvimento inaugura uma nova dinâmica na vida social, já que possibilita, de forma democrática e participativa, a inclusão de usuários na construção da própria rede, aperfeiçoando as interações, as comunidades virtuais, permitindo que atividades antes relegadas apenas a especialistas se tornassem disponíveis para qualquer cidadão. Assim, o jornalismo tradicional tem perdido espaço diante da dinâmica veloz das redes sociais e do jornalismo on-line, que desfrutam de maior autonomia editorial.

O jornal The Intercept ${ }^{2}$, por exemplo, se declara como uma premiada agência de notícias dedicada à responsabilização dos poderosos por meio de um jornalismo destemido e combativo, cuja missão é aprofundar as investigações, com análises implacáveis que se concentram em política, corrupção, meio ambiente, segurança pública, tecnologia, mídia e muito mais. Ainda, segundo informações contidas na página do jornal, concede aos seus jornalistas a liberdade editorial e o suporte legal de que precisam para expor a corrupção e a injustiça onde quer que as encontrem. Nesse sentido, sua política de combate ao governo não encontra as mesmas resistências que a mídia tradicional, já que conta com um programa de financiamento coletivo. O portal possui uma clara posição de denúncia sobre temas ligados à exploração e ilicitudes ambientais. No ano de 2017, a organização de notícias ganhou foi premiada no Awards for Reportingon The Environment, com a publicação da obra "O Estranho Caso de Tennie White", da autora Sharon Lerner, que abordou uma investigação minuciosa sobre contaminação e injustiça perto de uma fábrica de produtos químicos no Mississippi ${ }^{3}$.

${ }^{2}$ A versão brasileira do The Intercept Brasil foi inaugurada em 02 de agosto de 2016.
${ }^{3}$ Disponível em: https://www.sej.org/winners-sej-16th-annual-awards-reporting-environment_. Acesso em: 9 de nov. 2020. 
Já o portal O Antagonista é um site jornalístico, opinativo e investigativo criado pelos jornalistas Mario Sabino (ex-redator-chefe da Veja) e Diogo Mainardi (ex-colunista da Veja). Contou com a primeira publicação em agosto de 2015. Segundo aponta Pereira (2017), em março de 2016, O Antagonista se associou com o portal Empiricus Research, considerado a maior consultoria financeira do Brasil. Sobre a linha editorial do site, os próprios fundadores que dão a pista, na seção "A origem", no qual se intitulam como direita, sob o julgo de não frustrar seus leitores. O portal ficou conhecido por realizar extensa propaganda das manifestações favoráveis ao impeachment da ex-presidente Dilma Rousseff (PT), instigando a população a protestar, como também concedeu ampla cobertura sobre o evento. É considerado um portal avesso ao Partido dos Trabalhadores e seus membros, com reportagens que refletem ojeriza ao comunismo ou qualquer movimento que se intitule de esquerda.

Ainda que muitos acadêmicos refutem a categorização, os termos direita e esquerda foram apropriado por Bobbio (2011) pelos princípios da escolha da igualdade, sendo que para o autor a forma se manifesta pelo modo como é concebida a relação entre igualdade e desigualdade desses dois espectros políticos.

[...] Partindo do pressuposto, como eu fiz, de que a pessoa de esquerda é aquela que considera mais o que os homens tem em comum do que o que os divide, e de que a pessoa de direita, ao contrário, dá maior relevância política ao que diferencia um homem do outro do que ao que os une, a diferença entre direita e esquerda revela-se no fato de que, para a pessoa de esquerda, a igualdade é a regra e a desigualdade, a exceção (Bobbio, 2011, p. 23).

Da mesma linha, Savage (1985) aponta que a divisão esquerda-direita segue presente e se materializa na dualidade que atualmente caracteriza o debate entre materialistas e pós-materialistas, com temas como liberdade de expressão, combate ao crime e a violência, melhoria na qualidade do trabalho e proteção ao meio ambiente em oposição ao crescimento econômico, pode ser vista claramente através da relação esquerdadireita. Após intensa pesquisa bibliográfica, Marcelo Todt (2019) constata que a dicotomia esquerda-direita também traz impacto no consenso científico em torno da 
crise ambiental, sendo que os partidos de esquerda possuem maior abertura à causa ecológica.

O autor menciona que a pesquisa realizada no Reino Unido, por Whitmarsh (2011) identificou que a prevalência de ceticismo sobre a mudança climática é fortemente determinado pelos valores ambientais e políticos dos indivíduos, em detrimento a educação ou conhecimento. Ou seja, a variável mais forte relacionada ao ceticismo não é a falta de informação, sendo que os céticos do clima baseiam-se na ideologia e não na evidência. Em contrapartida, os indivíduos de esquerda se apoiam em valores próambientais e reconhecem a severidade das mudanças climáticas. Outra pesquisa, realizada nos Estados Unidos por Kahan (2015 apud Todt, 2019) obteve a mesma constatação ao identificar que $22 \%$ das pessoas identificadas com a direita acreditam que a atividade humana é a principal fonte de aquecimento global, contra cerca de $75 \%$ das pessoas identificadas com a esquerda.

No esfera midiática, tem-se como hipótese que os jornais também assumem posições distintas em relação a crise ambiental, em especial os portais independentes. Nesse sentido, esse artigo pretende responder como o desmonte das políticas públicas ambientais apareceu na cobertura das respectivas mídias? 0 artigo traz como pressuposto que mesmo diante da suposta democracia virtual, os respectivos jornais não enquadraram o debate sobre o desmonte das políticas públicas na Amazônia na perspectiva de conscientizar a opinião pública, prevalecendo uma narrativa que se deslocou para a polarização político-partidária e relegou para o segundo plano a dimensão ambiental.

\section{CONTEXTO DAS QUEIMADAS NA AMAZÔNIA E DA CRISE AMBIENTAL}

A crise ambiental vivenciada durante o governo de Jair Bolsonaro, como já visto anteriormente, vêm desde a nomeação de Ricardo Salles para Ministério do Meio Ambiente, o que desagradou ambientalistas e entidades ligadas ao setor. Porém o aumento das queimadas na Amazônia gerou uma crise diplomática e ganhou espaço na agenda dos meios de comunicação. A omissão do Estado na prevenção e combate permitiu que os incêndios na Amazônia aumentassem em níveis alarmantes. 
O número de queimadas no ano de 2019 é $84 \%$ superior ao registrado no país no mesmo período de 2018. E a maior parte dos incêndios, cerca de $52 \%$ do total (ou quase 40 mil focos), aconteceu em uma mesma região: a Amazônia. Essas informações foram lançadas pelo Instituto Nacional de Pesquisas Espaciais (INPE) e podem ser acompanhadas em tempo real pelo site do Programa Queimadas. As imagens coletadas pelo INPE são geradas por três satélites operados pela National Aeronautics and Space Administration (NASA).

O primeiro gráfico aponta os índices de queimadas desde 1998. No acumulado de nove meses e considerando os últimos dez anos, 2019 é o terceiro pior ano, já que registrou 66,7 mil focos de incêndio, ficando abaixo apenas de 2010 e 2017, que registraram 102 mil e 70,8 mil registros respectivamente. As informações despertam a atenção, sobretudo, diante das políticas de enfraquecimento de órgãos importante para o combate do desmatamento na Amazônia.

Gráfico 1. Série histórica das queimadas no Brasil

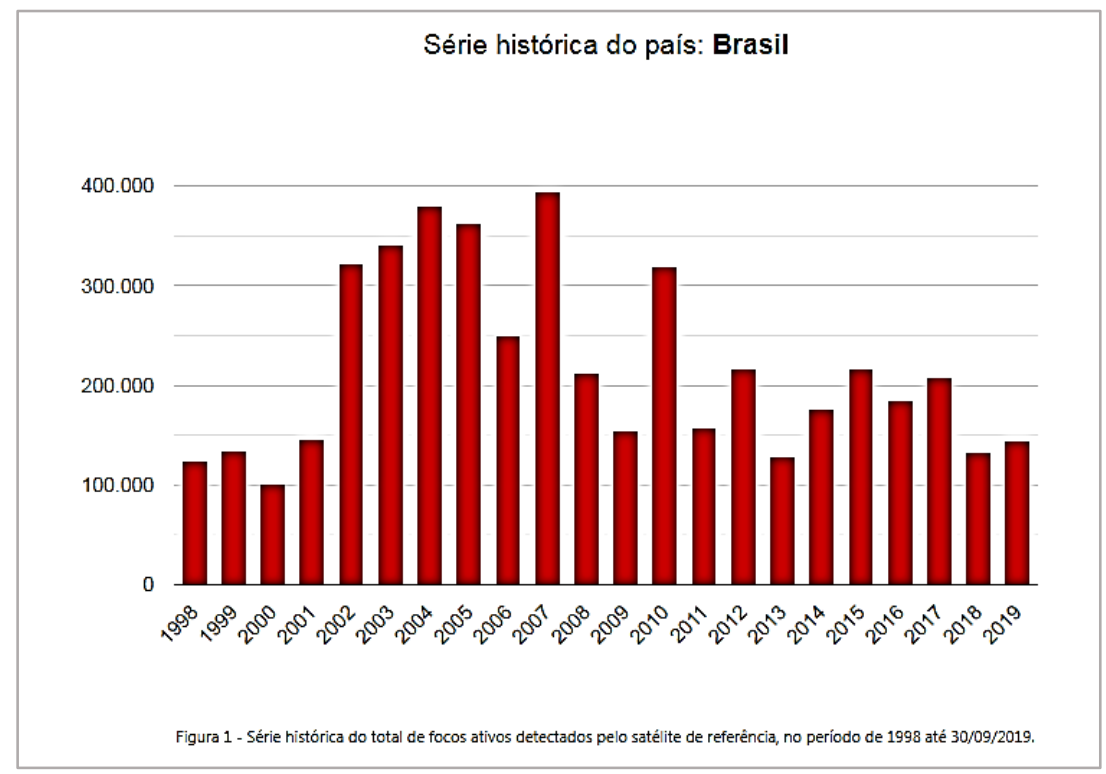

Fonte: INPE (Instituto Nacional de Pesquisas Espaciais)

O segundo gráfico aponta para os meses em que as queimadas mais estiveram presentes, com destaque para agosto e setembro de 2019.

Gráfico 2. Comparativo Sazonal 


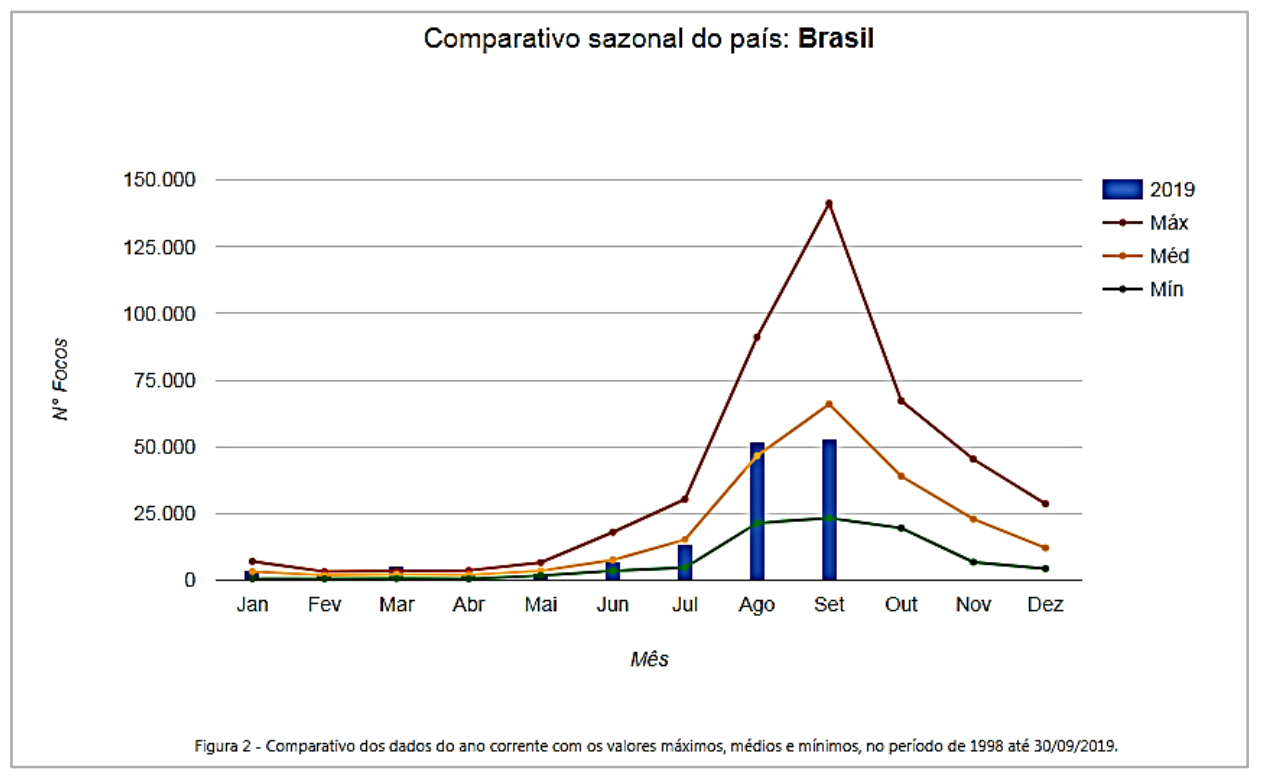

Fonte: INPE (Instituto Nacional de Pesquisas Espaciais)

A matéria publicada pelo site da BBC News Brasil,em 22 de agosto, com a chamada "Locais com mais queimadas também tiveram mais desmatamento" aponta uma correlação entre o desmatamento e as queimadas na Amazônia. Nota técnica divulgada por pesquisadores do Instituto de Pesquisa Ambiental da Amazônia (IPAM) e da Universidade Federal do Acre mostrou que o recente aumento no número das queimadas está diretamente relacionado com o desmatamento. Segundo aponta a reportagem, os dez municípios da região com mais alertas de desmatamento são também os que mais registraram focos de incêndio no ano de 2019.

Essa matéria contesta o argumento do governo de que os focos de incêndio seriam algo natural e corrobora a tese de que as políticas adotadas pelo governo têm fortalecido a destruição do bioma, diante do enfraquecimento de órgãos fiscalizadores como o IBAMA (Instituto Brasileiro do Meio Ambiente e dos Recursos Naturais Renováveis). Estima-se, segundo divulgação do INPE, que a destruição florestal subiu 93\% em comparação com os nove meses do ano anterior, totalizando 7.854 quilômetros quadrados entre janeiro e setembro de 2019.

O enfraquecimento de órgãos ambientais e de políticas públicas representa uma das causas da aceleração do desmatamento. Entre as ações do Ministério do Meio Ambiente, promovidas pelo governo atual, deve-se destacar a extinção de três 
secretarias, a saber: secretaria de mudanças do clima, secretaria de extrativismo e desenvolvimento rural sustentável e da secretaria de articulação institucional e cidadania ambiental (Decretos no 9672/19. Decreto no 9667/19). Além disso, registrase a perda de autonomia do IBAMA e do ICMbio que estão proibidos de divulgar qualquer informação e estabelecer uma comunicação direta com os jornalistas, sem a anuência do Ministério do Meio Ambiente. O governo também promoveu o enfraquecimento de políticas e estruturas indígenas, com a transferência do Licenciamento Ambiental de Terras indígenas da Fundação Nacional do Índio (FUNAI) para a Secretaria Especial de Assuntos Fundiários (SEAF/MAPA).

Entre condicionantes de maior impacto que alinham as queimadas ambientais ao desmatamento destaca-se a agropecuária. Ohashi et al. apontam (2018) que o rebanho bovino brasileiro cresceu 69\% entre o período de 1975 a 2017, segundo dados do último senso agropecuário liberado pelo Instituto Brasileiro de Geografia e Estatística (IBGE, 2018). O número de rebanho na Amazônia também apresentou um crescimento de 1066\%, passando de 5.119.585 para 59.682.788 cabeças de gado. Segundo os autores, uma das consequências desse crescimento é a derrubada da floresta para formação de pastagem cultivada, cuja área passou de 4.105.488 para 44.766.547 há (IBGE, 2018), o que representa um crescimento de 990,5\%. Outro problema está relacionada a formação da pastagem já que

a formação das pastagens foi realizada através de queimadas e sem nenhum critério técnico agroecológico, agravando o dano ambiental, especialmente em relação à preservação das matas ciliares das margens dos rios e das matas de preservação ao redor das nascentes, afetando principalmente os pequenos córregos, muitos dos quais outrora perenes, atualmente secam completamente na estação seca, afetando o volume dos rios nos quais deságuam (Ohashi et al., 2018, p. 203).

Entre os estados com maiores índices de rebanho bovino estão o Mato Grosso, Pará e Rondônia. Nesse sentido são esses os estados considerados responsáveis pelas maiores taxas de desmatamentos da Amazônia, segundo aponta o terceiro gráfico do INPE:

Gráfico 3. Desmatamento anual da Amazônia por Estado 


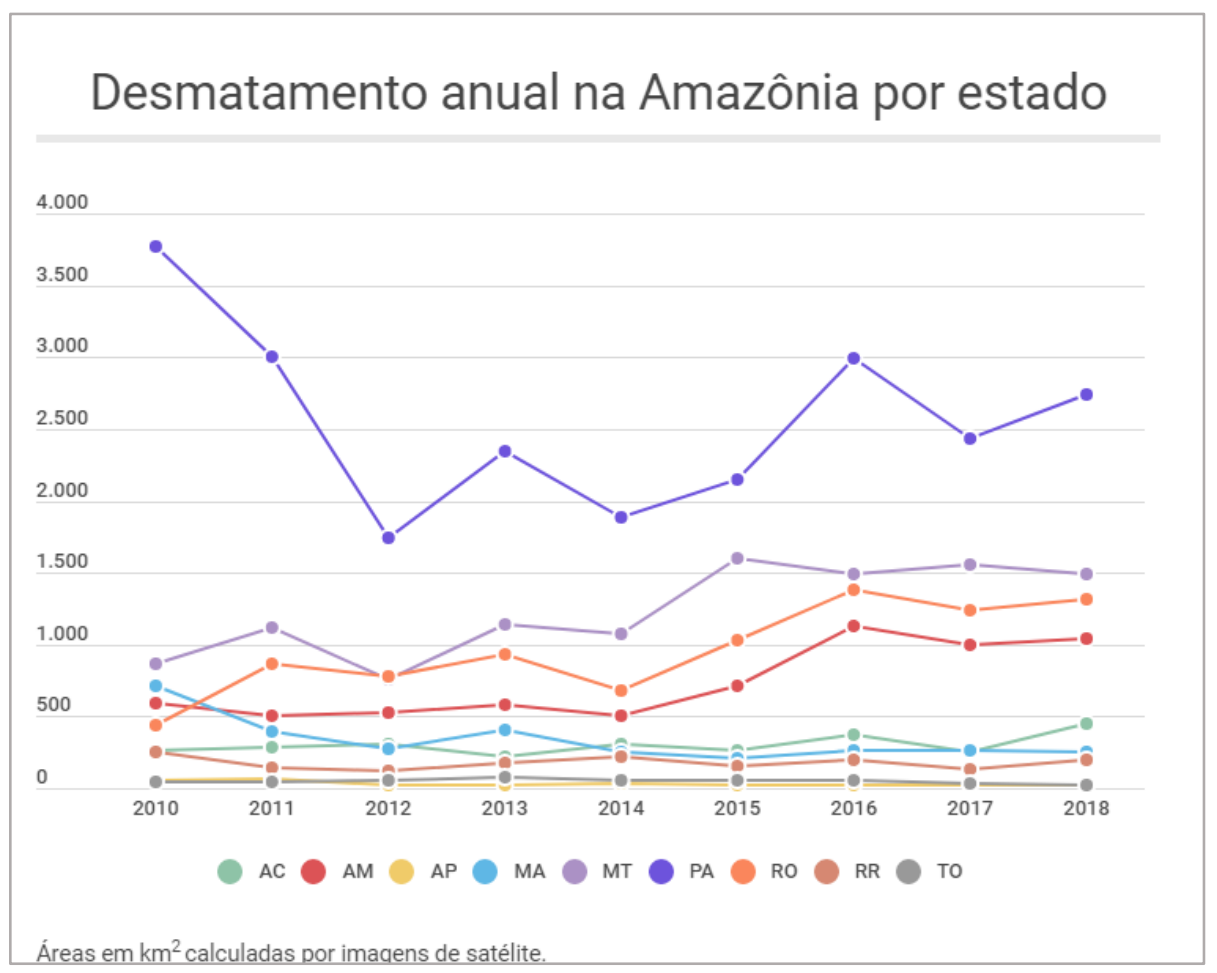

Fonte: INPE (Instituto Nacional de Pesquisas Espaciais)

A região leste do Pará se transformou nos últimos anos em uma frente de desmatamento e ocupação pela agropecuária. No ano de 2019, os municípios paraenses de Altamira e São Félix do Xingu eram os que apresentavam até agosto as maiores somas de áreas desmatadas da região. Na cidade de Novo Progresso, o incidente que ficou conhecido como "O Dia do Fogo", registrou 124 focos de incêndio ativos em 10 de agosto, um aumento de $300 \%$ em relação ao dia anterior. As cidades de Altamira e São Félix do Xingu também registraram um aumento de 179\% e 329\% respectivamente, entre os dias 9 e 11 de agosto.

Ainda em fase de investigação pela Polícia Federal e pelo Ministério Público Federal e cercado de especulações sobre a possibilidade de se tratar de um incêndio criminoso, promovido por produtores rurais da região Norte do país, com objetivo de chamar a atenção de autoridades para a necessidade de limpar as pastagens, "O Dia do Fogo", promoveu uma alerta nacional e internacional. Soma-se ao evento, a chuva negra que caiu na cidade de São Paulo, por volta das 15 horas, no dia 19 de agosto, após o céu da capital paulista escurecer. 
O coordenador do Programa Queimadas do Instituto Nacional de Pesquisas Espaciais (INPE), Alberto Setzer, avaliou que o fenômeno do dia escuro em São Paulo ocorreu pela junção das fumaças dos incêndios que consomem a floresta Amazônica e da presença de uma frente fria que chegava a cidade. Para o pesquisador: "o evento deve ser considerado como a combinação de duas condições coincidentes, porém de natureza física distinta: a entrada de uma frente de ar frio, e a presença de uma nuvem de fumaça proveniente de queimadas originadas a centenas e até milhares de km de distância"4.

Diante da repercussão midiática gerada com a crise das queimadas na Amazônia e seus efeitos visíveis, havia certa expectativa para o discurso do Presidente Bolsonaro, na 74a Assembleia-Geral da Organização das Nações Unidas, que ocorreu em Nova York (EUA), com início em 17 de setembro de 20190. Em relação à Amazônia, Bolsonaro defendeu a política ambiental que seu governo tem adotado e criticou as extensões de terras destinadas aos povos indígenas. Justificou que as queimadas são motivadas apenas por fatores sazonais e climáticos ${ }^{5}$.

\section{POLÍTICAS AMBIEITAIS NO BRASIL: BREVE PERCURSO HISTÓRICO}

Diante da discussão acerca da crise ambiental que acometeu o governo de Jair Bolsonaro (PSL) é fundamental a compreensão em torno da formulação de políticas públicas voltadas para a área ambiental ao longo dos anos. Dessa forma, é importante destacar que se compreende a política ambiental como um conjunto de normas, leis e ações públicas que visam à preservação ambiental e o desenvolvimento sustentável. Para Pena (2019), as políticas em torno das questões ambientais no país começaram a ser implementadas na década de 30, quando, se criaram parques nacionais, localizados em pontos onde ocorriam as expansões agrícolas e os consequentes processos de desmatamento.

Pena (2019) ainda destaca que na década de 50, com a expansão industrial que se intensificou no país, as políticas ambientais foram abandonadas e as ações em torno da

\footnotetext{
${ }^{4}$ Pesquisadores descrevem fenômeno que escureceu SP e sua relação com as queimadas na Amazônia. Disponível em: https://www.oeco.org.br/noticias/pesquisadores-descrevem-fenomeno-que-escureceu-sp-e-sua-relacao-com-as-queimadas-naamazonia/. Acesso em: 21 de out. de 2019.

${ }^{5} \mathrm{O}$ discurso de Bolsonaro na ONU teve repercussão midiática e trouxeram debates políticos e ambientais. Uma matéria trazida pelo jornal El País analisa o discurso do presidente, acesso ao link: https://brasil.elpais.com/brasil/2019/09/24/politica/1569340250_255091.html. Acesso em: 21 de out. de 2019.
} 
temática se estagnaram. Já na década de 60, algumas medidas foram realizadas, podendo destacar a promulgação do novo Código Florestal Brasileiro, que estabeleceu regras, dentre elas à criação das Áreas de Proteção Permanente. Devido às pressões de movimentos de ambientalistas e com a realização da Conferência de Estocolmo de 1972, o Brasil retomou a discussão em torno das questões ambientais e passou a desenvolver políticas públicas com mais direcionamento por parte dos setores governamentais. A partir daí houve a criação de diversos órgãos responsáveis pela preservação ambiental, dentre eles pode-se destacar o Instituto Brasileiro do Meio Ambiente e dos Recursos Naturais Renováveis (IBAMA). Com a promulgação da Constituição Federal de 1988, a política ambiental no Brasil teve seu maior avanço, conforme aponta Caraciolo (2002), pois se elaborou uma das leis ambientais mais avançadas do mundo, já que era voltada não só para os deveres dos cidadãos, mas também os deveres de instituições, empresas e até governos com relação à preservação ambiental. É nesse momento que a política ambiental adota um caráter mais voltado à fiscalização e ao cumprimento da lei.

A denominada bancada de deputados e senadores ruralista, que teve seu início em meados da década de 1980, cresceu em oposição ao Movimento dos Trabalhadores sem Terra (MST), que apareceu no cenário nacional com a finalidade de promover a distribuição de terras para famílias carentes e sem oportunidade de trabalho (propondo a chamada "Reforma Agrária", temática que ainda causa intensos debates pelo país). Diante do anseio de ambientalistas para um caminho alternativo para a conservação do meio ambiente em concordância com o uso dos recursos naturais para a produção e crescimento do país, tem início o debate sobre uma nova pauta, construído em torno do desenvolvimento sustentável.

É nesse momento que a bancada ruralista, segundo aponta Castelo (2005) visualiza a oportunidade de defender interesses ligados ao setor. Inaugura-se a discussão acerca da mudança do Código Florestal, com o argumento da necessidade de atualizar o Código brasileiro e modernizá-lo diante dos novos rumos do desenvolvimento sustentável. Segundo aponta Castelo, a bancada ruralista foi "altamente persuasiva nos debates governamentais a cerca do Novo Código Florestal" (2005, p. 28). Assim, em 2012 foi sancionado o polêmico Novo Código Florestal (Lei 12.651, de 2012), altamente criticado 
por ambientalistas por ser um retrocesso na legislação ambiental brasileira. Entre os pontos questionados está a redução das Áreas de Proteção Permanente e a anistia a crimes ambientais praticados por latifundiários.

Sérgio Leitão (2007) compara as políticas públicas dos governos Lula e FHC:

Lula e FHC prometeram marcar suas administrações com propostas diferenciadas de desenvolvimento, que dessem conta do desafio de compatibilizar o crescimento econômico com o uso sustentável do meio ambiente. Ambos quebraram as promessas feitas e agiram no sentido oposto do que haviam prometido, embora tenham mantido o discurso pró-ambiente, principalmente quando se tratava de definir uma imagem brasileira perante o público externo (Leitão, p. 1, 2007).

Dessa forma, Leitão critica os governos do PT e do PSDB, que apesar de terem adotado discursos em prol do desenvolvimento sustentável pouco fizeram em termos de políticas públicas e financiamento. Dessa forma, para o autor em 2007 já existia um retrocesso nas políticas ambientais que se confirmou em 2012, com o Novo Código Florestal.

Para Castelo (2015), durante a votação do Novo Código Florestal a mídia mostrou o conflito entre os agentes sociais como ambientalistas e produtores rurais, demonstrando um tipo de enquadramento que tem se tornado recorrente quanto à cobertura de questões ambientais. Apesar das políticas ambientais no Brasil vivenciarem períodos de retrocessos, e a flexibilização do uso dos recursos naturais nas atividades agrícolas tornarem-se uma prática apoiada por inúmeros políticos (Castelo, 2015), o jornalismo promove coberturas que abordam conflitos e disputas de interesses, em detrimento a uma abordagem que aponta os entraves para consolidação de políticas públicas ambientais e falta de ação dos governantes.

Com a aprovação do Novo Código Florestal, percebe-se que houve um retrocesso quanto à política ambiental no Brasil, tanto no aspecto da fiscalização quanto de legislação. Esse passo foi adotado por governos que antecederam o de Bolsonaro. Dessa forma, a discussão que se levanta é o motivo pelo qual o Presidente Bolsonaro têm sofrido ataques em função de sua política ambiental? Presume-se que um dos pontos da desavença está relacionado ao fato de Bolsonaro, diferentemente dos presidentes anteriores assumir abertamente seu 
compromisso com a bancada ruralista e renegar as ONGs e instituições ambientalistas. Além disso, seu governo tem adotado uma política ambiental que contrapõe as discussões dos últimos anos em relação ao desenvolvimento sustentável.

O Greenpeace Brasil divulgou recentemente as políticas elencadas por Bolsonaro nos primeiros 100 dias de governo. A primeira medida listada pela entidade refere-se ao esvaziamento do Ministério do Meio Ambiente, com a extinção de secretárias. Outro ponto refere-se às imprecisões nas competências para o Licenciamento Ambiental, favorecendo produtores rurais, consequentemente dando abertura para o desmatamento. Outra medida criticada pelo Greenpeace Brasil trata-se do enfraquecimento de políticas e estruturas indígenas, apoiando o fim das demarcações de terras indígenas. A liberação acelerada de agrotóxicos e o esvaziamento das políticas de segurança alimentar e nutricional também são criticados pela entidade. Outras medidas que não foram concretizadas, mas prometidas pelo governo também foram destacadas pelo Greenpeace Brasil ${ }^{6}$.

Discutir as políticas ambientais adotadas pelos governos nos últimos anos é fundamental, principalmente para compreender contexto atual. Ainda, acreditamos ser de grande relevância, destacado o papel do jornalismo como centralizador de acesso à informação, compreender como a mídia enquadrou a crise ambiental que se agravou no governo Bolsonaro e os retrocessos promovidos por esse governo em torno do enfraquecimento das políticas públicas para o setor.

\section{A TEORIA DO ENQUADRAMENTO COMO METODOLOGIA}

A crise ambiental tem sido objeto de debate na sociedade brasileira, promovido em grande medida pela repercussão midiática diante dos últimos acontecimentos envolvendo a região da Amazônia. Analisar como os jornais têm enquadrado a crise é importante, tendo em vista o papel que a mídia ocupa na formação da opinião pública.

\footnotetext{
${ }^{6}$ O quadro que lista "Ações efetivadas e promessas nos primeiros 100 dias de governo Bolsonaro", está disponível no site do Greenpeace- Brasil e pode ser acessado através do link: https://www.greenpeace.org.br/hubfs/atos-medidas-bolsonaro100dias.pdf
} 
O conceito de enquadramento se consolidou a partir de estudos voltados às teorias jornalísticas que analisam os efeitos políticos da mídia na construção da agenda pública. Para Motta (2007) no jornalismo prevalece como enquadramento predominante o frame narrativo. Baseado nos estudos de London, que traz como consideração o fato de os sujeitos possuírem experiências difusas e caleidoscópicas dos acontecimentos, passíveis de compreensão apenas por meio do agrupamento de itens com base na similaridade, o enquadramento tornou-se o mecanismo "inconsciente dos jornalistas para transmitir as ocorrências selecionadas de uma forma compreensível, tornando as questões políticas inteligíveis para o público" (Motta, 2007, p. 2).

O autor também aponta que para seduzir a atenção da audiência, o jornalismo político estimula o conflito, "traz as personagens políticas para a arena, convoca-as em acusações e respostas sucessivas. Se há oposições latentes na política, o jornalismo as promove, se não as há, ele as incita. Alimenta o confronto em sucessivas afirmações e desmentidos das fontes, promove hostilidades, exacerba os conflitos" (Motta, 2007, p. 9).

Não obstante, Porto (2002) alerta que "os usos da noção de enquadramento são tão numerosos e variados que surgem dúvidas quanto à possibilidade de construção de um marco teórico claro, sistemático e coerente a partir do conceito". Diante do surgimento de inúmeros estudos em torno de enquadramento, com análises do discurso da mídia nos diferentes campos sociais, Campos (2014) afirma que existe certa imprecisão teórica nos estudos em torno de enquadramento no que se refere aos estudos da interface mídia e política. A fim de delimitar metodologicamente os estudos de enquadramento que envolve a comunicação, a partir de Gamson e Modigliani (1993), busca-se a noção de "pacotes interpretativos", compreendendo que o enquadramento presume a articulação de determinados discursos em uma dada organização formal.

Maia e Vimieiro (2011) também discutem pacotes interpretativos e os definem como agrupamentos formados por determinados dispositivos simbólicos, que têm como essência o enquadramento. Segundo as autoras, os pacotes são definidos como certo padrão em um determinado texto, que se compõe de diversos elementos. 
Esses elementos não são palavras, mas componentes ou dispositivos dos enquadramentos previamente definidos. Ao invés de codificar os enquadramentos como um todo, nós sugerimos partir o enquadramento em seus elementos isolados, os quais devem ser facilmente codificados em uma análise de conteúdo. Depois disso, uma análise dos agrupamentos desses componentes deve revelar os enquadramentos. (Maia e Vimieiro, 2011, p. 241)

Esse tipo de análise reside em compreender o modo como os discursos estabelecem molduras de sentido, enquadrando o mundo a partir de percepções especificas (Mendoça e Simões, 2012). Dessa forma, serão elaborados "pacotes interpretativos" (Gamson e Modigliani, 1993; Maia e Vimieiro, 2011), a fim de compreender de forma comparativa os enquadramentos dados às queimadas na Amazônia, bem como a instabilidade política gerada com esse fato.

Como corpus de análise foi coletado todas as matérias veiculadas no jornal on-lineThe Intercept Brasil e no portal O Antagonista, que tinham como foco a crise ambiental no governo Bolsonaro e as queimadas na Amazônia. Como recorte, foi definido o período de 19 de agosto de 2019, quando houve grande repercussão midiática das queimadas devido à escuridão que se deu sobre o céu de São Paulo, até o dia 24 de setembro de 2019, quando o presidente Jair Bolsonaro discursou na 74으 Assembleia Geral das Nações Unidas (ONU), onde havia grande expectativa da mídia nacional e internacional sobre a posição do governo brasileiro sobre a situação da Amazônia.

Com o auxílio do software de análise qualitativa MAXQDA, identificaram-se os principais pacotes interpretativos, que se estruturaram em nove categorias de enquadramentos, a saber: (1) Oposição/ Críticas ao governo Bolsonaro (PSL); (2)Ações e Políticas Públicas do Governo;(3) Base aliada/Apoio ao governo Bolsonaro (PSL);(4) Crise política;(5) Crise econômica (6) Trajetória do ministro de Meio Ambiente Ricardo Salles (NOVO); (7) Apoio de países aliados ao governo;(8) Dados sobre as queimadas e (9) Críticas ao Agronegócio.

\subsection{ANÁLISE DO SITE THE INTERCEPT}


Durante o período analisado o jornal publicou sete reportagens que abordaram a temática das queimadas, sendo possível classificá-las em quatro categorias: (1) Oposição/ Críticas ao governo Bolsonaro (PSL);(2) Trajetória do ministro de Meio Ambiente Ricardo Salles (NOVO); (3) Críticas ao Agronegócio e (4) Ações e Políticas Públicas de governo.

Quadro 1. Enquadramento do site de notícias The Intercept Brasil

\begin{tabular}{|c|c|c|c|}
\hline Pacote interpretativo & $\begin{array}{l}\text { Descrição do tipo de } \\
\text { enquadramento }\end{array}$ & $\begin{array}{c}\text { Número de } \\
\text { noticias }\end{array}$ & Percentual \\
\hline $\begin{array}{l}\text { 1. Oposição/ Críticas } \\
\text { ao governo Bolsonaro } \\
\text { (PSL) }\end{array}$ & $\begin{array}{l}\text { Diz respeito a notícias com conteúdo } \\
\text { crítico seja por parte dos partidos da } \\
\text { oposição, de entidades e } \\
\text { ambientalistas ou mesmo de } \\
\text { articulistas e colunistas do site The } \\
\text { InterceptBrasil }\end{array}$ & 3 & $43 \%$ \\
\hline $\begin{array}{l}\text { 2. Trajetória do } \\
\text { Ministro de Meio } \\
\text { Ambiente Ricardo } \\
\text { Salles (NOVO) }\end{array}$ & $\begin{array}{c}\text { Relaciona-se a uma notícia que traz a } \\
\text { trajetória do ministro de Meio } \\
\text { Ambiente, Ricardo Salles (NOVO), } \\
\text { elencando o processo jurídico que } \\
\text { envolve o político }\end{array}$ & 1 & $14 \%$ \\
\hline $\begin{array}{l}\text { 3. Críticas ao } \\
\text { Agronegócio }\end{array}$ & $\begin{array}{l}\text { Relaciona-se a notícias que revelam o } \\
\text { desenvolvimento da pecuária na } \\
\text { região da Amazônia, o que contribui } \\
\text { para o desmatamento. }\end{array}$ & 2 & $29 \%$ \\
\hline $\begin{array}{l}\text { 4. Ações e Políticas } \\
\text { Públicas de governo }\end{array}$ & $\begin{array}{c}\text { Trata-se de notícias referentes a } \\
\text { políticas anunciadas pelo governo } \\
\text { para tratar da crise ambiental: } \\
\text { reuniões, ações, financiamentos, } \\
\text { assim como alterações nas políticas } \\
\text { públicas ambientais. }\end{array}$ & 1 & $14 \%$ \\
\hline TOTAL & & 7 & $100 \%$ \\
\hline
\end{tabular}

Fonte: autoria própria

Como fica evidente no Quadro 1, de um total de 7 notícias publicadas pelo site The Intercept Brasil sobre a crise ambiental no governo de Bolsonaro (PSL), um total de 3 (o que equivale a 43\%) referem-se ao enquadramento "Oposição/ Críticas as políticas do governo Bolsonaro (PSL)". Um total de 2 matérias referem-se à críticas ao Agronegócio de forma geral, tanto à exploração por parte de empresas brasileiras quanto americanas (o que equivale a $29 \%$ do total). Foi possível identificar apenas uma reportagem (o que equivale a $14 \%$ do total) nas categorias "Ações e Políticas Públicas de Governo" e "Trajetória do Ministro de Meio Ambiente Ricardo Salles (NOVO).

Diante da extensão da amostra, para efeito de análise qualitativa, se estabeleceu um recorte das reportagens que foram enquadradas na categoria "Ações e Políticas Públicas do 
governo. Nesse caso, apenas a reportagem do dia 12 de setembro, intitulada "Com apoio de irmão de Bolsonaro, ruralistas tentam impedir demarcação de terras indígenas em SP", se enquadrou nessa temática. A reportagem traz informações sobre a presença de Renato Bolsonaro, irmão do presidente, em uma sessão plenária na cidade de Maracatu, interior de São Paulo, que tratava da questão da demarcação de terras indígenas contestada por ruralistas. A matéria deixa claro o apoio do irmão do Presidente aos ruralistas e cita também o episódio da demissão de Renato Bolsonaro da Assembleia Legislativa de São Paulo, após uma denúncia do canal televisivo SBT, de que o mesmo "não aparecia para trabalhar, apesar do salário de 17 mil reais por mês". O site denuncia de maneira sucinta a proximidade entre o presidente Bolsonaro e o setor ruralista e traça um histórico de embate do governo com o Congresso e o Supremo Tribunal Federal, diante das tentativas de alteração nas políticas públicas de demarcação de terras indígenas.

\subsection{ANÁLISE DO PORTAL O ANTAGONISTA}

Durante o período das queimadas, O Antagonista publicou 280 notícias sobre o meio ambiente, sendo possível enquadrá-los em oito eixos interpretativos: (1) Oposição/ Críticas ao governo Bolsonaro (PSL); (2) Ações e Políticas Públicas do Governo; (3) Base aliada/Apoio ao governo Bolsonaro (PSL); (4) Crise política; (5) Crise econômica (6) Trajetória do ministro de Meio Ambiente Ricardo Salles (NOVO); (7) Apoio de países aliados ao governo e (8) Dados sobre as queimadas.

Como fica evidente no Quadro 2, de um total de 280 notícias publicadas pelo site $O$ Antagonista sobre a crise ambiental no governo Bolsonaro (PSL), um total de 70 notícias (o que equivale a 25\%) referem-se ao enquadramento "Ações e Políticas Públicas de governo". Um total de 90 notícias se relacionam com a crise política (o que equivale a $32 \%$ do total). O enquadramento referente à "base aliada/Apoio ao governo Bolsonaro (PSL)" aparece em 32 das 280 notícias analisadas (o equivalente à $11 \%$ do total). Os enquadramentos referentes à "Oposição/ Críticas ao governo Bolsonaro (PSL)" e "Apoio de países aliados ao governo" equivalem a cerca $10 \%$ do total de matérias analisadas cada. O eixo temático referente Consequências econômicas diante da crise ambiental aparece em 19 notícias (somando 7\% do total analisado). Por fim, os enquadramentos 
referentes aos "dados sobre as queimadas" e à "Crise política envolvendo o ministro

Ricardo Salles" aparecem menos nas matérias analisadas, com 8 e 6 notícias, respectivamente. Ambas somam cerca de $5 \%$ das matérias analisadas.

Quadro 2. Enquadramento do site de notícias O Antagonista

\begin{tabular}{|c|c|c|c|}
\hline Pacote interpretativo & $\begin{array}{l}\text { Descrição do tipo de } \\
\text { enquadramento }\end{array}$ & $\begin{array}{c}\text { Número de } \\
\text { notícias }\end{array}$ & Percentual \\
\hline $\begin{array}{l}\text { 1. Oposição/ Críticas } \\
\text { ao governo Bolsonaro } \\
\text { (PSL) }\end{array}$ & $\begin{array}{l}\text { Diz respeito a notícias com conteúdo } \\
\text { crítico seja por parte dos partidos da } \\
\text { oposição, de entidades e } \\
\text { ambientalistas ou mesmo de } \\
\text { articulistas e colunistas do veículo de } \\
\text { comunicação. }\end{array}$ & 27 & $10 \%$ \\
\hline $\begin{array}{l}\text { 2. Ações e Políticas } \\
\text { Públicas do Governo }\end{array}$ & $\begin{array}{c}\text { Trata-se de notícias referentes a } \\
\text { políticas anunciadas pelo governo } \\
\text { para tratar da crise ambiental: } \\
\text { reuniões, ações, financiamentos, } \\
\text { assim como alterações nas políticas } \\
\text { públicas ambientais. }\end{array}$ & 70 & $25 \%$ \\
\hline $\begin{array}{l}\text { 3. Base aliada/Apoio } \\
\text { ao governo Bolsonaro } \\
\text { (PSL) }\end{array}$ & $\begin{array}{l}\text { Diz respeito a notícias com conteúdo } \\
\text { mais favorável ao governo seja por } \\
\text { parte da base aliada, ou mesmo do } \\
\text { próprio veículo de notícias. }\end{array}$ & 32 & $11 \%$ \\
\hline Crise política & $\begin{array}{l}\text { Relaciona-se, a notícias, que, neste } \\
\text { caso, revelam a crise vivenciada pelo } \\
\text { governo do ponto de vista político. } \\
\text { São matérias referentes a pressões } \\
\text { vindas do Judiciário, da sociedade e } \\
\text { de entidades e países para que } \\
\text { providências fossem tomadas diante } \\
\text { da crise ambiental. }\end{array}$ & 90 & $32 \%$ \\
\hline 5. Crise econômica & $\begin{array}{l}\text { Relaciona-se a notícias que, para } \\
\text { demonstrar a dimensão da crise } \\
\text { ambiental, foca-se nas consequências } \\
\text { econômicas que estavam sendo } \\
\text { geradas ou que poderiam ocorrer } \\
\text { diante do quadro. }\end{array}$ & 19 & $7 \%$ \\
\hline $\begin{array}{l}\text { 6. Trajetória do } \\
\text { ministro de Meio } \\
\text { Ambiente Ricardo } \\
\text { Salles (NOVO) }\end{array}$ & $\begin{array}{c}\text { Diz respeito às notícias referentes à } \\
\text { perda de apoio de Ricardo Salles } \\
\text { dentro do governo e diante da } \\
\text { oposição, devido à crise ambiental } \\
\text { que vivenciara. }\end{array}$ & 6 & $2 \%$ \\
\hline $\begin{array}{l}\text { 7. Apoio de países } \\
\text { aliados ao governo }\end{array}$ & $\begin{array}{l}\text { Refere-se às notícias sobre o apoio } \\
\text { financeiro vindo de países aliados. }\end{array}$ & 28 & $10 \%$ \\
\hline $\begin{array}{l}\text { 8. Dados sobre as } \\
\text { queimadas }\end{array}$ & $\begin{array}{c}\text { Trata-se das notícias que trazem os } \\
\text { dados sobre os incêndios que } \\
\text { atingiam a Amazônia. }\end{array}$ & 8 & $3 \%$ \\
\hline TOTAL & & 280 & $100 \%$ \\
\hline
\end{tabular}

Fonte: autoria própria 
De maneira semelhante, se estabeleceu um recorte do conteúdo do portal $O$ Antagonista selecionando apenas as reportagens enquadradas na categoria "Ações e Políticas Públicas do governo". Do total de 70 matérias sobre o tema, apenas 20 trataram de questões inerentes as políticas ambientais no governo Bolsonaro, o que representa $7 \%$ do conteúdo total veiculado durante o período. As demais notícias destacaram as ações do governo no sentido de conter as queimadas.

Para efeito de análise qualitativa, buscamos as reportagens que trataram especificamente do desmonte das políticas ambientais, com objetivo de identificar como as ações do governo reverberaram na mídia. Do total de 20 reportagens que abordaram as políticas públicas do governo, 4 concederam voz ao Ministro do Meio Ambiente, Ricardo Salles que efetuou críticas em relação as ações de governos federais anteriores, além de negar que seu ministério atua na destruição de políticas ambientais. E o que traz a notícia, "'Têm muito pouca técnica e muita ideologia', diz Salles sobre regras ambientais", no qual o ministro acusa os governos anteriores de se ocuparem de políticas públicas irracionais. A matéria reproduz a crítica do ministro em torno das políticas adotadas nos últimos 20 anos, ao indicar a ausência de um plano de desenvolvimento sustentável para o setor.

Nas matérias "Ricardo Salles fala em 'campanha internacional' contra o governo Bolsonaro" e "Discurso na ONU será de esclarecimento sobre Amazônia, diz Salles", o ministro nega o bloqueio de políticas públicas e acusa as ONGs de efetuar ações para denegrir a imagem do governo, ao afirmar: "[Queremos] Desmistificar essa falsa ideia de que houve um desmonte do sistema ambiental, de que houve flexibilização da legislação ou da fiscalização, de que o Brasil não se importa com meio ambiente

O portal também concedeu voz ao Presidente Bolsonaro com 8 matérias em que 0 governante acusa ONGs ambientais e membro da oposição de conspirarem contra seu governo, além de insinuar que o aumento das queimadas são relatos infundados, por gente que sempre uso a Amazônia para fins políticos. Em inúmeros trechos das matérias veiculadas pelo portal, Bolsonaro ataca a questão da demarcação de terras indígenas e aponta que os índios foram usados como massa de manobra de governos petistas. Em 
matéria com o título "Já se extrapolou essa psicose no tocante a demarcação de terras, o presidente aponta sua visão sobre a política de demarcação: "Não sei se estivesse outro presidente aqui isso já tivesse sido demarcado ou não. O nosso sentimento aqui, a nossa decisão até o momento -mas vamos ouvir os governadores- é não demarcar mais isso aí".

No tocante a ações do governo no âmbito de políticas públicas, o portal veiculou 3 matérias que tratavam do decreto assinado por Bolsonaro proibindo as queimadas no território nacional por dois meses, exceto quando estiverem relacionadas com controle fitossanitário, e atividades agrícolas de subsistência por populações indígenas. As notícias também mencionavam o pacote ambiental em trâmite pelo governo Bolsonaro para combater o desmatamento da Amazônia.

Em relação às alterações na política ambiental promovida pelo governo, o portal veiculou 5 reportagens, sendo que duas abordaram as medidas adotadas pela oposição contra Bolsonaro e Salles. As matérias reproduziam o discurso de Deputados Federais do partido Novo e da Rede, que ingressaram no Supremo Tribunal Federal (STF) contra o governo, em função do descaso com a questão ambiental. A notícia com o título "Rede vai ao STF contra Bolsonaro e Salles por omissão no caso Amazônia", estabelece uma relação entre o desmonte da política ambiental e o crescimento do agronegócio, conforme segue: "A política governamental para a efetiva proteção do meio ambiente contra o desmatamento tem sido inexistente ou ínfima. Enquanto o Chefe do Executivo dá sinais ao mercado de que o desmatamento é bom e que promoverá o desenvolvimento do País, alguns indivíduos ligados ao mercado agrícola avançam sobre a floresta amazônica sem qualquer tutela do Estado."

O portal também publicou notícias que questionaram os dados do governo e apontaram o aumento excessivo das queimadas desde o início de 2019. Como exemplo, a matéria "Desmatamento na Amazônia aumentou mais de 200\%" (quem era presidente?), alertou: “Em um ano, o desmatamento na Amazônia aumentou mais de 200\%. No levantamento divulgado esta semana, foram derrubados 1.700 quilômetros quadrados de floresta nativa (num período de seis meses). A área desmatada é maior que a cidade 
de São Paulo. Comparando essa derrubada com o período anterior, o desmatamento na Amazônia aumentou 215\%". De maneira semelhante, a notícia "Questão da Amazônia despertou com ataques de Bolsonaro, diz ex-diretor do Inpe" reproduziu trechos da entrevista de Ricardo Galvão, ex-Diretor do INPE, que foi exonerado por Bolsonaro. Em reportagem ao jornal $O$ Estado de S. Paulo, Galvão alertou sobre a visão capitalista destruidora do presidente no que tange as políticas públicas ambientais.

Assim, intercalando entre uma narrativa governista e vozes críticas ao governo Bolsonaro, o desmonte de políticas públicas, como o fim da demarcação de terras indígenas e quilombolas, o descaso com o desmatamento e o impulso para a exploração agrícola e mineral na região da Amazônia, apareceram de maneira breve e descontextualizada no portal $O$ Antagonista, sem propor uma reflexão mais ampla sobre o tema. Apesar do portal se propor a noticiar fatos curtos, a plataforma digital permite trazer hiperlinks e outros recursos que levam o leitor a ter acesso a gráficos e dados mais elaborados, trazendo informações mais consolidadas cientificamente. Mas ao adotar um enquadramento mais polarizado, percebe-se que a mídia em questão optou por destacar as notícias de forma mais simplista, com enfoque maior na questão política.

\section{CONSIDERAÇÕES FINAIS}

Dentre as teorias contemporâneas do jornalismo, destaca-se o enquadramento que trabalha com a ideia de que os jornais, ao selecionarem determinados fatos, enfatizam alguns aspectos a partir de mapas culturais, excluindo outros elementos. Ao optar por um tipo de enquadramento, a mídia adota uma narrativa que pode ou não desvelar os principais aspectos relacionados a um acontecimento.

Isso pode ser observado na cobertura dos sites The Intercept Brasil e O Antagonista sobre a crise ambiental que atinge a floresta Amazônica. O desmatamento da Amazônia é uma das maiores tragédias ambientais, o que justificaria uma cobertura densa sobre o assunto, tendo em vista o afrouxamento das políticas públicas do governo Bolsonaro para a região. Apesar dos diferentes tipos de enquadramentos adotados pelos jornais, o primeiro traz reportagens de conteúdo mais abrangente e o segundo investe em matérias curtas e factuais, a discussão sobre as políticas públicas que envolvem a 
proteção ambiental foram abordadas de maneira sucinta. Mesmo que a questão ambiental esteja também ligada à política, trazer essa discussão para a polarização política em que se encontra o país torna-se uma problemática. Ambos os jornais buscaram discutir a questão das queimadas ou, para atacar o Governo Federal e suas políticas públicas, ou, para minimizar a situação. Essa visão simplista da situação tende a reforçar a polarização da temática ambiental ao mesmo tempo em que não se discute cientificamente o problema com a sociedade.

Dessa forma, com análise dos resultados constatou-se que os jornais apenas informaram, sem abordar de maneira contextualizada toda a dimensão do problema. A análise qualitativa dos textos indicou um jornalismo deficiente, com reportagens que repercutem e alimentam a polarização política, ainda que comportem enquadramentos distintos. Nesse cenário, a questão ambiental tornou-se objeto de especulações e embates entre mídias que divergem em termos político, sendo que o conteúdo veiculado pouco refletiu as ações controversas em torno dos possíveis reflexos das diretrizes adotadas pelo novo governo.

Esse trabalho é apenas um pequeno recorte diante da amplitude da temática. Além disso, a questão das queimadas no Brasil tem ganhado desdobramentos na mídia nacional e internacional, intensificando a necessidade de pesquisas no que se refere ao papel midiático no enquadramento das questões ambientais, tendo em vista o importante papel jornalístico em mediar o debate científico com a comunidade e ao mesmo tempo dar luz às políticas públicas.

\section{REFERÊNCIAS BIBLIOGRÁFICAS}

Braga, J. L. (2012). Circuitos versus campos sociais. Em M. A. Mattos, J. Janotti Júnior e N. Jacks (Org.). Mediação \& Midiatização (pp. 29-52). Salvador: EDUFBA.

Barros, A. T. de. (2017). A internet como mídia ambiental: Estratégias dos partidos políticos brasileiros. Ambiente \& Sociedade, 20(1), 187-206.

Bobbio, N. (2011). Direita e esquerda: razões e significados de uma distinção política. São Paulo: Unesp. 
Castelo, T. B. (2015). Legislação Florestal brasileira e políticas do governo de combate ao desmatamento na Amazônia Legal. Revista Ambiente \& Sociedade, 18(4), 221-242.

Campos, L. A. (2014) A identificação de enquadramentos através da análise de correspondências: um modelo analítico aplicado à controvérsia das ações afirmativas raciais na imprensa Revista Opinião Pública, 20(3), 377-406.

Caraciolo, P. M. de M. (2002). Apostila de Legislação Ambiental Sobre Licenciamento e Fiscalização Projeto: Reestruturação e Aperfeiçoamento do Licenciamento Ambiental da Região do Araripe -PE. Entidade Executora: SECTMA/CPRH. Publicado em Dez. 2002. Disponível em: http://dc179.4shared.com/doc/HJeQ0ijj/preview.html

Fernandes, C. M. (2015). Da mídia impressa à audiovisual: o agendamento intermidiático do escândalo da Petrobras no Jornal Nacional. Libero, 18(35), 111-122.

Gamson, W. e Modigliani, A. (1993). Media discourse and public opinion on nuclear power: a constructionist approach. American Journal of Sociology, 95, 1-37.

Goffman, E. (1986). Interaction ritual: Essays on face-to-face behavior. Nova York: Pantheon Books.

Leitão, S. (2007). Desafios ambientais: zerando o desmatamento na Amazônia. Planetaverde.org. Disponível em http://www.planetaverde.org/arquivos/biblioteca/arquivo_20131101095834_3831.pdf Machado, L. (2019). O que se sabe sobre o 'Dia do Fogo', momento-chave das queimadas na Amazônia. BBC News Brasil. Disponível em https://www.bbc.com/portuguese/brasil49453037

Maia, R. C. M. e Vimieiro, A. C. (2011). Enquadramentos da mídia e o processo de aprendizado social: transformação na cultura pública sobre o tema da deficiência de 1960 a 2008. E-compós, 14(1), 1-22.

Mendoça, R. F. Simões, P. G. (2012). Enquadramento: Diferentes operacionalizações analíticas de um conceito. Revista Brasileira de Ciências Sociais (RBCS), 27(79), 187-235. 
Motta, L. G. (2007). Enquadramentos Lúdico-dramáticos no Jornalismo: mapas culturais para organizar conflitos políticos. Intexto, 2(17), 1-25.

Ohashi, M. O. (2018). Desafio da Pecuária na Amazônia frente ao novo código florestal brasileiro. Em: Congresso Norte e Nordeste de Reprodução Animal (pp. 202-205), 9, 2018, Belém.

Pena, R. F. A. Política Ambiental no Brasil. Brasil Escola. Disponível em https://brasilescola.uol.com.br/brasil/politica-ambiental-no-brasil.htm .

Penteado, C. C. e Fortunato, I. (2015). Mídia e Políticas Públicas: possíveis campos exploratórios. Revista Brasileira de Ciências Sociais, 30(87), 129-142.

Pereira, A. L. (2017). A Nossa Bandeira Jamais Será Vermelha: a Luta Contra as Esquerdas em 1964 e 2016. Em Congresso de Ciências da Comunicação na Região Sudeste (pp. 115), 22., 2017, Volta Redonda. Rio de Janeiro: Intercom.

Porto, M. (2002). Media Framing and Citizen Competence: Television and Audiences' Interpretations of Politics in Brazil. Tese de doutorado, University of California, San Diego.

Todt, M. (2019). Agenda ecológica: o dualismo esquerda-direita e a clivagem ambiental na esquerda. Revista Latinoamericana de Estudio sen Cultura y Sociedad, 2(5), 1-13.

Savage, J. (1985). Postmaterialism of the Left and Right: Political Conflict in Postindustrial Society. Comparative Political Studies, 17(4), 431-451.

Whitmarsh, L. (2011). Scepticism and uncertainty about climate change: dimensions, determinants and change over time. Global Environmental Change, 21, 690-700. 